\title{
Pastoral Popular Luterana: o testemunho de uma prática
}

\author{
Grassroots Lutheran Ministry: the witness of a practice
}

Flávio Schmitt

\begin{abstract}
Resumo
A migração é parte da caminhada de povos e culturas. Em geral, migrantes são portadores de crenças e costumes. Ao partir levam consigo valores, tradições e crenças. Com os migrantes que deram origem à igreja luterana no Brasil não foi diferente. Além dos elementos culturais trazidos da Europa, ao se deslocarem dentro do território brasileiro, carregam consigo os elementos trazidos do estrangeiro e os agregados na nova pátria. Desta amálgama de valores, tradições e crenças vividas em diferentes contextos e desafios, brotam novas possibilidades e iniciativas. É este o cenário que dá origem à Pastoral Popular Luterana. Trata-se de uma iniciativa protagonizada majoritariamente por descendentes de imigrantes, vinculados à igreja luterana, e que procuram fazer frente aos desafios de um tempo particular. Este artigo trata da presença e atuação da Pastoral Popular Luterana no Oeste do Estado do Paraná, na década de 1980. Tem o propósito de tematizar a tarefa pastoral da igreja e fazer memória de uma prática.
\end{abstract}

\section{Palavras-chave}

Pastoral Popular Luterana. Migração. Testemunho. Igreja. Movimento Popular.

\begin{abstract}
Migration is part of the journey of peoples and cultures. In general, migrants carry with them beliefs and customs. When they leave they take with them values, traditions and beliefs. With the migrants who gave origin to the Lutheran Church in Brazil it was no different. Besides the cultural elements brought from Europe, when moving within the Brazilian territory, they carry with them the elements brought from outside the country and the ones acquired in the new country. From this amalgam of values, traditions and beliefs lived out in different contexts and challenges new possibilities and initiatives emerge. This is the scenario which gives origin to the Grassroots Lutheran Ministry. It is about an initiative protagonized mainly by descendants of migrants tied to the Lutheran church and who seek to confront the challenges of a particular time. This article deals with the presence and work of the Grassroots Lutheran
\end{abstract}

[Texto recebido em setembro de 2016 e aceito em junho de 2017, com base na avaliação cega por pares realizada por pareceristas ad hoc]

* Doutor em Ciências da Religião (UMESP). Professor na Faculdades EST, em São Leopoldo. E-mail: flavio@est.edu.br 
Ministry in the West of the state of Paraná in the decade of 1980. It has the goal of thematizing the pastoral task of the church and produce a memory of a practice.

Keywords

Grassroots Lutheran Ministry. Migration. Witness. Church. Grassroots Movement

\section{Introdução}

Falar de Pastoral Popular Luterana (PPL) é falar da paixão, do sonho e da esperança alimentados por centenas de cristãos luteranos espalhados pelo território brasileiro. A convicção de que pela luta, pela organização e esforço coletivo seria possível transformar as injustas estruturas da sociedade capitalista brasileira num mundo mais humano e fraterno inspirou o engajamento social e político motivado pela fé. Ligar fé e vida, integrar a dimensão material e espiritual, e viver o amor de Deus na forma de serviço à libertação dos pobres e oprimidos serviu como bússola desta caminhada.

Contudo, falar de Pastoral Popular Luterana também é falar da dor, do sofrimento, das lágrimas. A história da PPL também é uma história de muita dor, humilhação e incompreensão, dentro e fora da Igreja. Muitas foram as feridas abertas nos grupos, nas comunidades. Na medida em que as contradições e os reais interesses, muitas vezes articulados através das estruturas religiosas, foram sendo colocados em evidência e clareados, os conflitos, desencontros e rupturas não tardaram em se manifestar.

O presente texto procura fazer memória da inserção pastoral luterana no meio popular. Movimentos, associações, grupos organizados, sindicatos, partidos e lutas sociais são o placo onde a participação luterana se articula no meio do povo. Mais precisamente, trata-se de resgatar a participação da PPL no âmbito do atual Sínodo Rio Paraná da Igreja Evangélica de Confissão Luterana no Brasil (IECLB).

\section{O começo}

A Pastoral Popular Luterana nasce no final dos anos 1970 e início dos anos 1980. É fruto da leitura e compromisso de cristãos luteranos com a causa do povo brasileiro e luterano, vista a partir do Evangelho de Jesus Cristo e da tradição luterana.

Na origem da PPL estão pessoas preocupadas e envolvidas com o movimento popular. Da luta, na e pela terra, da luta sindical e da inserção partidária, cristãos luteranos visualizam a necessidade de preparar pessoas para dar conta da sua fé cristã luterana no movimento popular.

Os primeiros passos acontecem quase que simultaneamente no Rio Grande do Sul e no Estado do Espírito Santo. Inicialmente um grupo de acadêmicos de teologia abandona seus estudos para buscar uma inserção no mundo metalúrgico e rural. Esta opção vem 
acompanhada de leituras e estudos que permitem uma análise da realidade de tal maneira que nela se identifica a situação de opressão e exploração causada pela relação de dominação imposta pelo capitalismo.

A análise do capitalismo na perspectiva marxista conduz a rupturas. A situação impõe um processo de identificação com o povo e suas causas como condição para a fidelidade ao projeto de Deus revelado em Jesus. Por isso, não obstante a leitura da realidade com a ferramenta da análise marxista, a motivação para uma postura compromissada com o povo é fundamentalmente teológica. Parte do Deus da vida, o Libertador, que em Jesus Cristo se revela de forma plena. Nesta perspectiva, também a Leitura Popular da Bíblia se torna norteadora. ${ }^{1}$

A disseminação da PPL pelo território nacional se dá por meio das lutas populares. A cada ano mais e mais pessoas luteranas são desafiadas a contribuir no processo de libertação que se constrói a partir destas lutas populares. A inserção nas lutas exige organização. Para assessorar, para acompanhar, para capacitar, para animar na fé e celebrar, surge a PPL.

A estruturação da PPL nacional acontece aos poucos. Segue a própria estrutura de organização da IECLB. Nas comunidades, surgem os grupos de pessoas que buscam alimentar a luta social e política a partir de sua condição de cristãos luteranos. Nestes grupos que se formam no âmbito das comunidades são definidos os caminhos da luta e da organização.

Depois, segue a organização à nível de Paróquia. Neste âmbito mais amplo, a solidariedade e o compromisso mútuo passam a ser articulados. Representantes das paróquias, por sua vez, contribuem com a articulação regional. Antes da reestruturação, através das Regiões Eclesiásticas. Atualmente, através dos Sínodos. ${ }^{2}$

\section{Antecedentes}

A PPL é fruto de toda uma conjuntura política, social e econômica do seu tempo. A América Latina experimenta décadas de efervescência popular e de repressão militar. Em todo continente, de modo especial no Chile, na Nicarágua, em El Salvador e no Brasil, a preocupação e abertura da Igreja permite a irrupção do povo no seu seio. É a entrada dos pobres que trazem consigo para dentro da Igreja uma imensa riqueza, de luta e esperança. Com efeito, eles se ligam historicamente a Sepé Tiaraju, a Zumbi dos Palmares, a Canudos do Conselheiro e, mais recentemente, às Ligas Camponesas do Nordeste e a Trombas e Formoso do Centro Oeste.

1 SCHWANTES, Milton. Jacó é pequeno (Visões em Amós 7-9). Revista de Interpretação Bíblica LatinoAmericana, São Bernardo do Campo, n. 1, p. 81-92, 1988. p. 82ss.

2 Veja PRESENÇA DA IGREJA EVANGÉLICA DE CONFISSÃO LUTERANA NO BRASIL. Disponível em: <http://www.luteranos.com.br/conteudo/comunidades-paroquias-sinodos-a-ieclb-mais-perto-devoce>. Acesso em: 14 maio 2016. 
A PPL nasce no embalo do movimento de redemocratização do Brasil. O surgimento da PPL está na mesma linha de intenção que deu origem à Comissão Pastoral da Terra, Movimento dos Agricultores Sem-Terra e Movimento dos Atingidos por Barragens. Havia uma demanda social reprimida pelo regime militar instaurado a partir de 1964. Aos poucos, o povo começa a perder o medo de lutar contra o governo e reivindicar seus direitos.

A década de 1970 deixou suas marcas na história brasileira e paranaense. Por um lado, o intenso processo de colonização que consolidou o Oeste do Paraná como uma fronteira agrícola da moderna agricultura brasileira. O pacote da Revolução Verde evidenciou todo seu potencial ao longo desta década com a destruição de milhares de hectares de floresta e a implantação da monocultura da soja. Ao lado da agricultura, o desenvolvimento de toda uma cadeia produtiva voltada para a agroindústria da carne, especialmente suína e de frangos. Por outro lado, as contradições que este modo vai disseminando contribuem para o êxodo e a favelização rural.

Neste contexto de expansão do projeto capitalista de produção surgem os conflitos ligados à terra. Como se não bastassem as dificuldades já existentes, ligadas à produção e comercialização, os agricultores do extremo Oeste são surpreendidos com o projeto de construção da barragem de Itaipu.

A Igreja é convocada a ser voz das inúmeras famílias que passam a ser prejudicadas nas negociações em torno da indenização de suas terras. A partir desta organização e mobilização dos agricultores surge, mais tarde, o Movimento dos Atingidos por Barragens. Anos depois, a PPL viria a se alimentar da luta dos atingidos pela construção da barragem de Itaipu.

Nesta mesma década, surgem algumas das organizações que haveriam de travar um embate desigual para defender a causa dos trabalhadores na agricultura brasileira.

Embora tenha sido criada em Goiânia, em 1975, a ação da Comissão Pastoral da Terra (CPT) só se consolidou no Rio Grande do Sul em 1978. A CPT será uma parceira importante da Igreja Evangélica de Confissão Luterana no Brasil na luta pela defesa dos interesses, principalmente, dos agricultores da região. De acordo com o entendimento da pastoral, era necessário conscientizar e organizar os camponeses para lutarem pelos seus direitos. ${ }^{3}$

A origem do Movimento dos Trabalhadores Rurais Sem-Terra (MST) ${ }^{4}$ também está ligada às comunidades de base e à Pastoral da Terra. No decorrer dos anos 1980, o

\footnotetext{
COMISSÃO PASTORAL DA TERRA - CPT. Disponível em: <http:/ / www.cptnacional.org.br/index.php/sobre-nos/historico>. Acesso em: 14 jun. 2016.

4 MOVIMENTO SEM TERRA - MST. Disponível em: <http://www.mst.org.br/nossa-historia/>. Acesso em: 14 jun. 2016.
} 
MST ganha autonomia da igreja, incorpora elementos marxistas na análise da estrutura rural brasileira e no seu programa agrário de inspiração socialista.

A trajetória do MST está diretamente relacionada com a história da concentração fundiária que marca o Brasil desde 1500. O Movimento nasce da articulação das lutas pela terra que ocorreram de forma isolada no sul do Brasil na década de 1970. Em 1984, acontece o I Encontro Nacional do Movimento Sem Terra na cidade de Cascavel. Neste encontro são definidos os princípios, a forma de organização e reivindicações do movimento. No ano seguinte, realiza-se o I Congresso Nacional em Curitiba.

Todas essas lutas e bandeiras defendidas pelo movimento popular figuram como pano de fundo para o surgimento da PPL.

\section{A Igreja}

A presença de evangélico-luteranos no sul do Brasil está diretamente relacionada com as intrigas sociais e políticas ocorridas na Europa nos séculos XIX e início do século XX. Como resultado de um conjunto de fatores do Velho Mundo, milhares de migrantes deixaram suas raízes e buscaram novos espaços para constituição de seus ideais no Novo Mundo.

Este processo migratório tem continuidade no solo brasileiro. A partir da segunda metade do século $\mathrm{XX}$ a atenção se volta para a região banhada por um dos principais rios da Bacia Platina: o Rio Paraná, que, em sentido latitudinal, divide os países do Brasil e do Paraguai.

O Estado brasileiro fomentou o processo de colonização através de políticas públicas de estimulo à ocupação da porção ocidental do país, viabilizada por empresas colonizadoras. ${ }^{5}$

Os evangélico-luteranos vindos do Estado do Rio Grande do Sul e de Santa Catarina, que tomaram parte nesse processo, trouxeram consigo fortes traços culturais identificados com a herança europeia, mais precisamente com as raízes étnicas germânicas. ${ }^{6}$ Contudo, não obstante as dificuldades iniciais, esta gente imediatamente tratou de formar comunidades e edificar seus templos. Das iniciativas pioneiras, surgem inúmeras comunidades espalhadas pela região Sudeste, Oeste e Norte do Estado do Paraná. Em meio as lutas, angústias e esperança desta gente, nasce a PPL.

5 No extremo Oeste, destaca-se a empresa colonizadora Industrial Madeireira Colonizadora S/A - Maripá, responsável pela colonização de municípios como Toledo, Palotina e Marechal Cândido Rondon.

6 DREHER, Martin Norberto. Igreja e Germanidade. São Leopoldo: Sinodal, 1984. Também VITECK, Harto. Imigração Alemã no Paraná: 180 anos: 1829-2009. Marechal Cândido Rondon: Germânica, 2011. 


\section{A proposta}

A PPL nasce como fruto de toda uma caminhada de Igreja junto às pessoas luteranas exploradas e injustiçadas pela realidade fundiária, agravada ainda mais com a concretização de projetos como a construção de Itaipu. Nesse sentido, a PPL é a confluência de esforços junto com a CPT, movimento popular e partidos políticos articulados por luteranos no âmbito do Oeste do Paraná. Ao mesmo tempo em que se alimenta da luta do passado, a PPL também se propõe a articular a continuidade da luta no presente.

A criação e estruturação da PPL no Oeste do Paraná acontece no ano de 1986. Havia o propósito e a necessidade de articular as iniciativas luteranas de inserção popular. Obreiros e leigos engajados no movimento popular articulam a criação e posterior aprovação da PPL da $5^{a}$ Região Eclesiástica em Concílio Regional. As tensões e conflitos internos decorrentes deste encaminhamento viriam a acompanhar a Igreja ao longo de praticamente uma década. Afinal, havia também, como há até hoje, pessoas luteranas que alimentam uma visão e postura política diferente da assumida pela PPL.

A partir de sua criação, a PPL $5^{\text {a }}$ Região, como se tornou conhecida, passou a desenvolver uma série de atividades intra e extraeclesiais. No âmbito interno, foi elaborado o livreto Igreja, Povo e Palavra para servir de subsídio aos grupos nas comunidades, seja no que diz respeito à mística como na questão de consciência política. Além de oferecer subsídios de leitura bíblica, canto e orações, este material faz uma leitura social, econômica, política e ideológica da realidade brasileira de então.

Também surgiram várias iniciativas nas comunidades com a utilização de símbolos (terra, semente, plantas, etc.) como recursos litúrgicos nas celebrações. Além disso, a PPL introduz na $5^{\text {a }}$ Região toda uma hinologia voltada ao enriquecimento das celebrações. Os cânticos passaram a expressar aspectos da luta popular e num ritmo popular. O Cancioneiro da PPL passa a ser o hinário de muitas comunidades, inclusive.

A PPL desenvolve todo um projeto de conscientização de seus militantes visando uma maior inserção deles nos presbitérios das comunidades. A presença e participação de pessoas luteranas com opções políticas e interesses diferentes dos que até então ocupavam estas funções, trouxe muitos conflitos e tensões, para comunidades, lideranças e obreiros.

Do ponto de vista institucional, foi de fundamental importância para a caminhada da PPL na $5^{\text {a }}$ Região a doação de uma coleta, realizada por ocasião do Kirchentag realizado em Berlim em meados de 1986, pela Igreja Evangélica da Alemanha.

Os recursos oriundos desta doação possibilitaram a estruturação da sede da PPL, inicialmente em Santa Helena e depois transferida para Toledo; a criação de uma infraestrutura, bem como os recursos destinados aos cursos de formação, despesas de viagens e encontros e auxílios diversos. 
Além de constituir sua sede em Toledo e adquirir um carro, a PPL também contratou uma pessoa para atuar como secretário executivo da entidade. A pessoa liberada para esta atividade foi Vítor Lieven. Antes de assumir o trabalho da PPL na Região, Vítor trabalhada no GTME, no Mato Grosso, na defesa da causa indígena. Sua experiência e comprometimento com a causa dos excluídos foi fundamental para o desenvolvimento das atividades da PPL neste novo cenário.

Esta estrutura, embora mínima, foi determinante no processo de articulação e mobilização da PPL no Oeste do Paraná. Embora houvesse obreiros envolvidos, seus compromissos pastorais limitavam por demais as ações a atividades que eram desenvolvidas. Também os leigos manifestavam suas limitações. Com uma pessoa leiga liberada, a PPL também pode se articular melhor com outros grupos e entidades envolvidos nas lutas populares, inclusive com a PPL a nível Nacional.

Uma das atividades mais importantes da PPL foi o processo de constituição e acompanhamento de Associações de Pequenos Agricultores. A primeira iniciativa surgiu em Entre Rios do Oeste, onde um grupo de pequenos agricultores das Linhas São Clemente e Linha União se uniram e formaram uma associação. A associação tinha o propósito de fortalecer as iniciativas dos agricultores na hora da aquisição de insumos, sementes e comercialização da produção. Com auxílio da juventude da Igreja Evangélica da Baviera, este grupo adquiriu um trator e os implementos necessitados pelos agricultores. Esta iniciativa serviu de exemplo para outros agricultores tanto do Paraná com de outros estados do país.

Posteriormente, foram criadas associações no âmbito da Paróquia de Pato Bragado, reunindo agricultores das localidades de Linha Itapiranga e Oriental e no Distrito de Margarida. Embora com propostas inovadoras na área da organização e produção, estes grupos organizados aos poucos foram se rendendo ao poder do mercado. Ao não operar uma ruptura com o modelo de agricultura agroexportador, tornaram-se seus reféns.

Nesta mesma linha de preocupação com os pequenos agricultores, a PPL passou a se envolver cada vez mais com a luta dos agricultores sem terra na região. As primeiras ações de apoio e solidariedade aconteceram no Sudoeste, onde obreiros e leigos não ficaram indiferentes às ocupações de terra que aí aconteceram. Depois surgiu a oportunidade de manifestar solidariedade com os sem terra da região de Roncador. Várias paróquias realizaram ofertas, recolheram doações em forma de roupas, alimento e lona para auxiliar aqueles que estavam lutando por um pedaço de chão. Nestas iniciativas, a PPL atuou em colaboração com o Movimento dos Trabalhadores Rurais Sem Terra (MST) e Comissão Pastoral da Terra (CPT) do Paraná.

Durante os últimos anos da década de 1980, a PPL esteve mais presente junto aos agricultores acampados e posteriormente assentados no município de Ibema. Além de 
inúmeras doações em forma de roupas, sementes e lonas, a PPL também contribuiu com estes sem-terra viabilizando a assistência técnica aos assentados.

Em toda essa inserção no mundo rural e agrícola, a PPL parte do princípio de que a terra é de Deus e que, portanto, deve estar a serviço da vida de seus filhos e não de quem tem dinheiro. Outra compreensão que explica essa inserção diz respeito à realidade fundiária do Brasil que sempre foi excludente e concentradora.

Num tempo em que computador e internet ainda não faziam parte da vida das pessoas, a PPL tratou de criar um veículo de comunicação com o objetivo principal de compartilhar informações importantes para a luta popular luterana. Este jornal chamado Partilha posteriormente foi assumido pelo Sínodo Rio Paraná e hoje é o jornal oficial deste Sínodo.

Outro campo em que a PPL foi pioneira no Oeste diz respeito à questão das mulheres. Desde o início, a PPL sempre contou com a colaboração de mulheres luteranas engajadas no movimento social. A presença das mulheres chamava a atenção para uma infinidade de direitos que a mulher agricultora não desfrutava naquela oportunidade (aposentadoria, auxílio maternidade, etc.). Ponto alto desta luta foi o encontro de mulheres que a PPL ajudou a organizar em Toledo e que contou com a presença da futura prefeita de São Paulo, Luiza Erundina.

A PPL desempenhou um relevante serviço na medida em que manifestou sua solidariedade para com agricultores brasileiros expulsos da Gleba Zampieri no Paraguai. Além de acolher e assessorar, inclusive juridicamente, a PPL se encarregou de entregar os agricultores ao Cônsul brasileiro no vizinho país e autoridades paraguaias. "Brasiguaios" passaram a ter na PPL um ponto de apoio para sua causa.

A PPL sempre manifestou uma grande preocupação na área da saúde. Além de condenar o uso indiscriminado de agrotóxicos pelos agricultores, conscientizar as pessoas acerca das questões ambientais, proporcionar palestras e cursos com especialistas na área da prevenção e tratamento de doenças, a PPL procurou fomentar novas iniciativas na área da saúde.

Além dos muitos encontros com especialistas em saúde popular, saúde alternativa e práticas tradicionais de cura, a PPL organizou cursos e encontros visando conscientizar pessoas a respeito da importância da alimentação no processo de busca e manutenção da saúde. Toda esta caminhada ligada à saúde culmina na criação do horto medicinal instalado inicialmente junto à casa paroquial no município de Mercedes.

Nesta linha de conscientização acerca da prevenção e manutenção da saúde, especialmente do homem e da mulher agricultora, a PPL não mediu esforços no sentido de chamar a atenção para o uso indiscriminado de agrotóxicos nas mais diferentes culturas e as consequências desta prática para o meio ambiente e para as futuras gerações. 
Entre as iniciativas da PPL para fora dos muros da Igreja está a participação na realização da Romaria da Terra no Paraná. Além de mobilizar seus fiéis para participar na Romaria, a PPL contribuiu significativamente na organização e coordenação das romarias em Lapa, São João do Ivaí, Medianeira e Coronel Vivida. Este trabalho conjunto com a CPT, tornou possível ainda outras atividades conjuntas, como os cursos de Formação.

Outra área de atuação importante para a PPL foi a Formação. A PPL, juntamente com CEBI, CPT e $5^{\text {a }}$ Região Eclesiástica, organizava anualmente, na Casa de Retiros de Cascavel, um seminário sobre Leitura Popular da Bíblia. Na assessoria destes seminários estiveram biblistas como Frei Gilberto Gorgulho, Marcelo Barros e Uwe Wegner. Estes seminários ecumênicos contavam com a participação de padres, freiras, pastores, pastoras, agentes de pastoral, presbíteros, leigos católicos e luteranos de todo Estado do Paraná.

Além desta formação, a PPL possibilitou a participação de luteranos na formação política oferecida pelo Centro de Formação Urbano Rural Irmã Araújo (CEFURIA) 7 e no Instituto Universidade Popular (UNIPOP) ${ }^{8}$ em Belém, no Pará. Também foram organizados seminários e encontros de formação sobre Leitura Popular da Bíblia em parceria com o Centro de Estudos Bíblicos (CEBI). ${ }^{9}$

A PPL também organizou Seminários de Formação, tendo como tema a conscientização política e análise de conjuntura. Nestes encontros havia uma vivência de espiritualidade muito intensa e rica, com cânticos, encenações e celebrações.

Marca da presença e serviço prestado pela PPL foi a criação da ACEMPRE, em Marechal Cândido Rondon. Nascida para ser instrumento de fortalecimento da agricultura familiar no âmbito da região de Marechal Cândido Rondon, hoje esta associação se ocupa em comercializar produtos orgânicos.

No seu propósito de estar a serviço do Evangelho de Jesus Cristo, a PPL da $5^{\text {a }}$ Região Eclesiástica da IECLB procurou acompanhar, assessorar e mobilizar pessoas, especialmente luteranos, para atuar dentro e fora da Igreja. Para tanto, foram desenvolvidas inúmeras atividades, como reuniões, encontros, seminários, cursos e

7 O Centro de Formação Urbano Rural Irmã Araújo (CEFURIA) é uma organização da sociedade civil que atua a partir da educação popular e da formação política, para o fortalecimento da organização popular em Curitiba, Região Metropolitana e outros municípios do interior do Paraná. Maiores informações em: CENTRO DE FORMAÇÃO URBANO RURAL IRMÃ ARAÚJO - CEFÚRIA. Disponível em: <http://www.cefuria.org.br/quem-somos/>. Acesso em: 14 jun. 2016.

8 O Instituto Universidade Popular (UNIPOP) é uma entidade civil, sem fins lucrativos, de Utilidade Pública Estadual (Lei n. 5.797, de 17 de outubro de 1994) e Utilidade Pública Municipal (Lei n. 8.275, de 14 de outubro de 2003). Nasceu da mobilização de um conjunto de entidades, movimentos sociais e igrejas comprometidas com a teologia da libertação, para ser um espaço plural de formação de lideranças populares, agentes pastorais e fortalecimento da democracia. INSTITUTO UNIVERSIDADE POPULAR - $\quad$ UNIPOP. Disponível em: <http://www.unipop.org.br/conteudos/institucional/1627>. Acesso em: 14 jun. 2016.

9 CENTRO DE ESTUDOS BÍBLICOS - CEBI. Disponível em: <http:// www.cebi.org.br/noticias.php?tipo=institucional\&secaold=52>. Acesso em: 14 jun. 2016. 
celebrações. Esta caminhada, fruto de muitas mãos, evidencia toda a vitalidade de um momento da IECLB, principalmente, no Oeste e Sudoeste do Paraná.

Um dos momentos mais significativos desta caminhada foi a realização do encontro nacional Celebrar Jeitos, em Marechal Candido Rondon em 2002.

\section{Desfecho}

Toda essa caminhada de PPL $5^{\text {a }}$ Região Eclesiástica aos poucos foi sendo desarticulada. Para esta desarticulação, contribuíram vários fatores. O panorama político internacional inaugurado pela década de 1990, a globalização, a situação política interna, bem como questões internas da própria IECLB contribuíram para uma redefinição e quase extinção da PPL na extinta $5^{\mathrm{a}}$ Região Eclesiástica, hoje PPL Sínodo Rio Paraná.

A transferência de obreiros, as novas prioridades na Igreja, uma visão diferente de Ministério, do próprio papel da Igreja e da relação com os movimentos sociais, o fim das utopias e o esgotamento de algumas formas de luta são alguns dos ingredientes que têm ajudando a nocautear a outrora vibrante caminha pastoral da PPL.

Boa parte das atividades ligadas à agricultura e assessoria aos agricultores no âmbito da então $5^{\text {a }}$ Região Eclesiástica passou a ser assumida pelo Centro de Apoio ao Pequeno Agricultor (CAPA), ${ }^{10}$ que também se tornou o herdeiro do patrimônio da PPL. Diferente do trabalho mais político e social da PPL, o CAPA tem priorizado a assistência técnica à agricultura orgânica.

Subsiste na PPL o trabalho das mulheres luteranas. Obreiras e leigas têm realizado encontros, seminários para discutir e aprofundar a questão das relações de gênero dentro e fora da Igreja. Mas também esta é uma caminhada diferente daquela trilhada no passado.

Não obstante a situação da PPL no Sínodo Rio Paraná na atualidade, as sementes foram lançadas. A PPL figura na história do Oeste do Paraná como símbolo da luta de uma gente que motivada pela sua fé, cristã luterana, se engaja nos movimentos sociais de seu tempo.

10 O antigo Centro de Apoio ao Pequeno Agricultor agora é denominado de Centro de Apoio e Promoção da Agroecologia (CAPA). O CAPA é uma organização da sociedade civil, vinculada à Igreja Evangélica de Confissão Luterana no Brasil, com atuação nos três estados do sul do Brasil: Rio Grande do Sul, Santa Catarina e Paraná. Criado em 1978, iniciou suas atividades em 15 de junho de 1979, na cidade de Santa Rosa (RS), com o nome de Centro de Aconselhamento ao Pequeno Agricultor. CENTRO DE APOIO E PROMOÇÃO DA AGROECOLOGIA (CAPA). Disponível em: <http://www.capa.org.br/page/historia/>. Acesso em: 14 jun. 2016. 


\section{Referências}

CENTRO DE APOIO E PROMOÇÃO DA AGROECOLOGIA (CAPA). Disponível em: <http://www.capa.org.br/page/historia/>. Acesso em: 14 jun. 2016.

CENTRO DE ESTUDOS BÍBLICOS - CEBI. Disponível em:

<http:/ / www.cebi.org.br/noticias.php?tipo=institucional\&secaold=52>. Acesso em: 14 jun. 2016.

CENTRO DE FORMAÇÃO URBANO RURAL IRMÃ ARAÚJO - CEFÚRIA. Disponível em: <http:/ / www.cefuria.org.br/quem-somos/>. Acesso em: 14 jun. 2016.

COMISSÃO PASTORAL DA TERRA - CPT. Disponível em:

<http://www.cptnacional.org.br/index.php/sobre-nos/historico>. Acesso em: 14 jun. 2016.

DREHER, Martin Norberto. Igreja e Germanidade. São Leopoldo: Sinodal, 1984.

INSTITUTO UNIVERSIDADE POPULAR - UNIPOP. Disponível em:

<http://www.unipop.org.br/conteudos/institucional/1627>. Acesso em: 14 jun. 2016.

MOVIMENTO SEM TERRA - MST. Disponível em: <http:/ / www.mst.org.br/nossahistoria/>. Acesso em: 14 jun. 2016.

PRESENÇA DA IGREJA EVANGÉLICA DE CONFISSÃO LUTERANA NO BRASIL. Disponível em: <http:/ / www.luteranos.com.br/conteudo/comunidades-paroquiassinodos-a-ieclb-mais-perto-de-voce>. Acesso em: 14 maio 2016.

SCHWANTES, Milton. Jacó é pequeno (Visões em Amós 7-9). Revista de Interpretação Bíblica Latino-Americana, São Bernardo do Campo, n. 1, p. 81-92, 1988.

VITECK, Harto. Imigração Alemã no Paraná: 180 anos: 1829-2009. Marechal Cândido Rondon: Germânica, 2011. 